\title{
Research on the Incentive Mechanism of PE Teachers in Shaanxi Non - governmental Colleges and Universities
}

\author{
Dehou $\mathrm{Ma}^{1, \mathrm{a}}$ \\ ${ }^{1}$ Xi'an Peihua University, Xi'an, Shaanxi, China, 710125 \\ aemail,
}

\begin{abstract}
Keywords: Incentive Mechanism, PE Teachers, Shaanxi Non-governmental Colleges and
\end{abstract} Universities

\begin{abstract}
This study intends to combine the social psychology, social management and other multi-disciplinary knowledge to carry out investigation and analysis of the work of physical education teachers to reflect the status quo and the existing problems of Shaanxi private colleges and universities teachers' incentive mechanism. In order to improve the cultivation of physical education teachers, the full mobilization of the enthusiasm of the majority of physical education teachers, to play their creativity, improve the quality and effectiveness of school physical education.
\end{abstract}

\section{Introduction}

Shaanxi private colleges and universities in the new round of development to achieve new breakthroughs, from the beginning of the development of the extension of the development of the connotation of development, the key is to strengthen the teaching staff and discipline construction, improve teaching quality. This is the eternal theme of college work, but also the lifeline of the survival and development of the school. Teachers are the first resource of the school and the main body of teaching, private colleges and universities to sustainable development of the core competitiveness, determines its talent training and education development success or failure. It is an important link to improve the quality of education in colleges and universities. Only by establishing an effective teacher incentive mechanism can we give full play to the enthusiasm, initiative and creativity of teachers' work in order to improve the performance of teachers in order to improve the quality of education and the efficiency of running schools, and provide a source of power for the sustainable development of colleges and universities. The teachers of private colleges and universities are composed of four parts of the full-time teachers of the school, part-time teachers of public institutions, retired teachers and graduate students, doctoral students. Private teachers in colleges and universities constitute a complex, age structure was bimodal, the teacher turnover rate is relatively high, and in the pay treatment, social security, social status, psychological satisfaction and other aspects at a disadvantage, making private colleges in the introduction of talent, use and stability there are many difficulties. Therefore, how to introduce more and better teachers under the restriction of limited resources, to stimulate the enthusiasm and creativity of teachers, to stabilize the teachers to reduce the wastage rate, need private colleges and universities to understand the psychological needs of teachers to meet the needs of teachers, using a variety of Incentives, the establishment of effective incentive mechanism.

It is an important aspect to cultivate the talents of private colleges and universities, and the level of teachers 'team directly affects the students' learning and the effect of teaching. For the private colleges and universities, with the transformation of modern educational ideas and re-understanding of the guiding ideology of education, private college physical education training objectives show a diversified development characteristics, the new era of quality education to promote and develop, need Private college school sports should have a scientific organization and a good organizational environment, only the scientific management mechanism to play the enthusiasm and creativity of teachers. College physical education teaching activities mainly rely on physical education teachers, physical education teachers in the process of physical education initiative, teaching level and teaching effect to determine the quality of physical education. Shaanxi is Chinese education 
province, but also Chinese western region science and technology education base, now Shaanxi private colleges in the country in a leading position, with a typical. Therefore, it is very important to strengthen the training of PE teachers and encouragement in private colleges and universities.

\section{The Shortcomings of Shaanxi Private Colleges and Universities Sports Development}

College teachers' ideological and moral, operational ability, psychological quality and cultural knowledge level are low. Private colleges and universities are different from other specialities of public institutions, private colleges and universities to strengthen the construction of teachers in order to ensure the full promotion of quality education. The management of private colleges and universities will have to fully mobilize the enthusiasm of teachers, teachers do the work as a fundamental, to establish suitable for private colleges and universities of their own characteristics of the effective protection of teachers. Management is to use effective means to mobilize and develop such human resources.

There are many loopholes of physical education teachers in private colleges and universities in Shaanxi Province, and the proportion of teachers is not harmonious. The proportion of young teachers is relatively large, the proportion of male and female teachers is unreasonable, the proportion of middle-aged teachers over 40 years old is too small, the degree of physical education teachers is mainly undergraduate and the proportion of master's degree is small. Physical education teacher title is unreasonable and senior titles too few teachers, junior titles too many teachers, and the lack of effective teacher management. Through the investigation, the author understands that many of the existing policies of teachers in Shaanxi private colleges have not been able to effectively play the incentive role. On the contrary, some policies have hindered the realization of good work motive of private college teachers, the lack of effective management system of private colleges and universities, Long-term incentive mechanism. The key to the development of teachers is the scientific management and effective incentive mechanism, the introduction of new quality education for the reform of sports teaching provides a new platform. Some research shows that college teachers should update their own knowledge structure from teaching, research, professional ethics, their own special quality, professional theoretical knowledge, mutual cooperation ability and so on, and effectively improve their own comprehensive ability and quality of physical education teachers. Therefore, the management of private colleges and universities must reflect the humanistic core, improve the quality of physical education teachers, establish a reasonable structure of teachers, establish effective incentive mechanism and restraint laws and regulations to promote material incentives and spiritual incentives both the new management system, The managers need to create conditions to meet the needs of managers, to promote the comprehensive and healthy development of teachers, which will become the primary responsibility of school management in order to effectively stimulate the creativity of teachers. Shaanxi private colleges and universities to manage around to encourage teachers, especially as private colleges and universities of the physical education teachers, because of their professional constraints, as well as private colleges and universities on the importance of physical education and other reasons, to stimulate the creativity of physical education teachers. The leaders and managers of private colleges and universities cannot be limited to the management work, but should turn to each teacher, the managers of physical education teachers should be from the school physical education teaching arrangements, the school rules and regulations management system revision, school organization, the most important thing is to put the interests of teachers on the most important position, teacher-oriented, better to stimulate the enthusiasm of teachers work and enthusiasm to speed up the construction of teachers.

\section{The Definition of Incentives}

From a management point of view, in the period of scientific management theory, incentives are defined as "things that do what they want to do", which has a clear causative nature. With the emergence of behavioral science theory, the definition of motivation extends to the reflection of the incentive object and the initiative, Robbins believes that motivation is through a high level of effort 
to achieve the goal of organizational goals, and this effort to be able to meet some of the individual need to be conditional. Liu Zheng Zhou believes that "the so-called incentive refers to the organization through the design of appropriate external forms of compensation and work environment, with certain behavioral norms and punitive measures, with information communication, to stimulate, guide, maintain and standardize member behavior to effectively achieve Organization and individual activities of its members."

From a psychological point of view, McLeod believes that "motivation is the use of emotional power." McGregor and others argue that "motivation is to guide individuals or groups with their own needs and personality, to work towards the goals of the organization, and to achieve their goals." Cheng Fangzheng that the incentive is a certain stimulus to stimulate people's motives, people have a share of the power, towards the desired goal of the psychological and behavioral process. Zhang Kai is the incentive to achieve a certain group or organizational goals, managers through the creation of a certain environment and conditions, activate the individual one or some psychological goals, to enhance the psychological and behavioral organization, control and regulation, and Driving the individual to make sustained and effective work efforts, and strive to achieve their own psychological goals and organizational goals of the process.

To sum up, the incentive is based on the individual and the group as the object of implementation, according to the characteristics of human needs, in the management of a guide to maximize the motive to stimulate people to induce people's behavior, to mobilize the enthusiasm and initiative, in order to achieve the organization's expected goal of the power process.

\section{The Definition of Incentive Mechanism}

Incentive mechanism is the "incentive" the specific role of the way, refers to the organization system, managers through the use of supporting the system, the introduction of external rewards and punishments, standardize the requirements, to stimulate the individual needs to stimulate the individual's work motivation, Individual behavior, to make its inherent potential, in the process of stimulating the overall goal and individual goals, and make the individual to achieve the pursuit of the goal and strive for a way, means or strategy. Organizational goals, incentives, motivate employees, incentive rules are organizational incentive mechanism constitutes the basic elements.

Teacher motivation mechanism is the education manager in order to achieve the established goal of the work, the use of a series of teachers to stimulate the inherent potential to make it feel that the use of force, only show, labor income, merit, self-conscious efforts to the expected goal of forging ahead of the method, measures and procedures in general, is a fully mobilize the enthusiasm of teachers and creative dynamic organizational system.

\section{The Implementation of the Incentive Mechanism for PE Teachers in Private Colleges and Universities in Shaanxi Province}

Establish Physical Teacher Goal Management Incentive Mechanism. Objective management emphasizes that the goal is both a means and a purpose, emphasizing full participation, attention to human personality, and taking full account of the relationship between the various levels of the organization. The essence of physical education is a goal to achieve the management process. The introduction of target management is conducive to clarify the direction of the development of private sports education, is conducive to mobilize the enthusiasm of the work of physical education teachers is conducive to strengthening and improving the private institutions of physical education and training. In the process of target management, we must pay attention to the use of spiritual encouragement, material incentives and other incentives, as the goal to achieve the necessary human resources to achieve the objectives of the management of physical education and training management objectives, material, financial and other support.

Build Physical Teacher Emotional Management Incentive Mechanism. Most of the characters of physical education teachers are more outgoing and rich in feelings. In the management of PE teachers in private colleges, institutional constraints are important, but it is a practical way for 
PE teachers to release energy as much as possible. Emotion is the attitude and experience that people make to meet the needs of human beings. It is the psychological function of mankind. Studies have shown that people are only in a pleasant and harmonious atmosphere, the state of the state of excitement is likely to give full play to their talents, to make creative performance. Psychology research shows that people's needs are the source of their enthusiasm, initiative and creativity, and the higher the level of human needs, the higher the proportion of mental and emotional factors.

Incentive Mechanism Helps to Improve the Moral Quality and Special Business Quality of Physical Education Teachers. Shaanxi private college teachers are characterized by young teachers and teachers, low academic qualifications, low title. In order to effectively change this unreasonable phenomenon, the managers of private colleges and universities should pay attention to the re-training of teachers, increase teachers' continuing education funds, establish corresponding incentive mechanism, promote more young teachers to improve their education, improve the overall quality of teachers the According to the existing problems of PE teachers in private colleges and universities in Shaanxi Province, we should increase the training of young teachers, including special technology, theoretical level and advanced educational ideas, so as to improve the overall level of PE teachers in Shaanxi private colleges. In addition, but also to carry out the physical education of teachers and moral education, to explore the spiritual power of physical education teachers, so that physical education teachers can really teach people.

Private Colleges and Universities Establish and Improve Fittest Incentive System. Shaanxi private colleges and universities set up a short time, the management is not perfect. With the expansion of the size of the school, the increase in the number of students, the school should step up to improve the management of institutions, so that it is conducive to the overall development of the school. In the private colleges and universities at the beginning of the school, the teacher's employment system is unreasonable, just to increase the number of teachers, teachers are not strict introduction. In order to adapt to the development of new higher education, we must change the original teacher management mode, in the introduction of talent to do "rather lack of abuse", and further strict the introduction of the principle of college PE teachers in the appointment of teachers, Be fair and equitable. The existing personnel system in private colleges and universities in Shaanxi Province is imperfect, so it is necessary to intensify and improve the personnel system, enhance the social status of PE teachers in private colleges and expand the introduction of physical education teachers, so as to improve the situation of the lack of physical education teachers in private colleges and universities in Shaanxi Province. In today's social market competition is becoming increasingly fierce and the social role of college PE teachers has changed. In the process of physical education, physical education teachers play a leading role, which correspondingly requires the improvement of the overall quality of physical education teachers to change the traditional concept of teachers need to have a scientific competition mechanism to improve teachers' enthusiasm and enthusiasm for their work, In the physical education, group competition, college students amateur extracurricular training, teachers, scientific research and improve the level of business ability level, etc., should have a corresponding incentive system, an effective incentive.

\section{Conclusion}

Teachers are the pillars of the survival of colleges and universities, how to organize the management system, what incentives to take, how to establish the incentive mechanism to get the best play of the enthusiasm of teachers and the effective operation of colleges and universities, colleges and universities should explore this important issue, involving all aspects of personnel management in colleges and universities. It is of great significance to study the incentive mechanism of teachers in private colleges and universities in Shaanxi Province, which is of great significance to stabilize the teachers 'team and encourage teachers' teaching enthusiasm and work performance. At the same time, it is of great importance to improve the quality of private higher education and the healthy development of colleges and universities. 


\section{References}

[1] Li Weimin. Shaanxi private higher education development of the new features [J]. Private Education Research. 2008 (04)

[2] Liu Yu, Hu Yang, Zhang Qian. Research on the Incentive Mechanism of Teachers in Non-governmental Institutions of Higher Learning[J]. Productivity Research. 2008 (10)

[3] Cao Lichen, Gu Danxia. [J]. Enterprise Technology Development. 2008 (05)

[4] Yang Yan. College teachers incentive mechanism - based on the needs of college teachers analysis [J]. Reading and writing (Education and Education Journal). 2008 (02)

[5] Wang Xin, Yao Conglie. College teacher incentive mechanism model design [J]. Journal of Jixi University (2007)

[6] Du Hongke, Huo Yongquan, Liu Shaolin, Duan Haijun. Shaanxi province private university teachers team construction research report [J]. Private Education Research. 2007 (06) 